\title{
Exacerbation of ulcerative colitis following administration of 5-ASA enemas
}

Barbara A. Young, BSc, Phm. Robin S. MCLeod, MD, FRCSC, Zane Cohen. MD, FRCSC

\begin{abstract}
A 33-year-old female with a 15 year history of ulcerative colitis presented with worsening diarrhea following colectomy and ileorectal anastomosis six months previously. Following administration of 5-ASA enemas (Salofalk). the patient developed abdominal cramps, nausea and vomiting, and severe diarrhea resulting in hypotension. Symptoms abated quickly when the 5-ASA enemas were discontinued. Although diarrhea and abdominal cramps have been described previously as side effects of oral sulfasalazine, oral 5-ASA and sulfasalazine enemas, this is the first report of these symptoms occurring following administration of 5-ASA enemas. Can J Gastroenterol 1989;3(2):50-52
\end{abstract}

Key Words: 5-Aminosalicylic acid (5-ASA), Drug induced colitis

\section{L'exacerbation de la colite ulcéreuse suite à l'administration de lavements au 5-ASA}

RESUME: Une patiente âgée de 33 ans et atteinte de colite ulcéreuse depuis 15 années a souffert de diarrhée aggravée après une colectomie et une anastomose iléo-rectale effectuées six mois plus tôt. Suite à l'injection de lavements de 5-ASA (Salofalk; Interfalk), elle a été prise de crampes abdominales, de nausées et de vomissements et d'une diarrhée sévère résultant en une hypotension. Les symptômes ont rapidement diminué après l'arrêt des lavements de 5-ASA. Bien que la diarrhée et les crampes abdominales aient été décrites auparavant comme appartenant aux effets secondaires de la sulfasalazine et du 5-ASA pris par voie buccale, et aux lavements de sulfasalazine, ce rapport est le premier qui relie les symptômes aux lavements de 5-ASA.

Dieision of General Surgery and Departments of Surgery and Phamacy. Toronto General Hospital and Unitersity of Toronto. Toronto. Ontario

Correspondence and reprints Dr R S McLeod. Toronto General Hospital, 200 Elizabeth Street. en 9-242, Toronto, Ontario M 5G 2C4. Telephone (519) 595.4952

Received for publication May 6, 1988 . Accepted October 3, 1988
ULFASALAZINE IS AN EFFECTIVE agent in the management of ulcerative colitis. There is accumulating clinical evidence that the salicylate moiety. 5 -aminosalicylic acid (5-ASA), is the active component, while sulfapyridine acts as a carrier molecule $(1-3)$. In the colon, the diazo bond which joins the two molecules is cleaved, releasing 5-ASA which acts locally to decrease inflammation. Unfortunately, the use of sulfasalazine may be limited due to intolerance or allergic reactions. It is estimated that up to $20 \%$ of patients may develop adverse reactions to sulfasalazine including nausea, vomiting, headache, fever, rash, hepatic and pulmonary dysfunction, and blood dyscrasias (4.5). Most of these reactions appear to be due to the sulpha moiety (6). Thus, new 5-ASA preparations have recently become available which may be tolerated by patients who had adverse reactions to sulfasalazine. However, there are a few reports of patients who have experienced similar reactions while taking oral 5-ASA (7-9).

A patient with ulcerative colitis who developed adverse reactions to sulfasalazine and 5-ASA, both orally (Asacol; 
Norwich Eaton) and rectally (Salofalk: Interfalk) is reported

\section{CASE PRESENTATION}

A 33-year-old fermale was admitted to the Toronto General Hospital in October 1987 with a 15 year history of ulcerative colitis. In 1972, the patient presented with diarrhea, nausea and vomiting, malaise and weight loss. Barium enema and sigmoidoscopy were both normal. Six months later the patient presented complaining of approximately 10 bloody bowel movements per day. Sigmoidoscopy and barium enema were consistent with panulcerative colitis. The patient was started on sulfasalazine $2 \mathrm{~g} /$ day. Within two days, nausea and continuous vomiting developed and diarrhea worsened. The symptoms resolved within hours of discontinuing the sulfasalazine. The patient was then successfully treated with prednisone and remained symptom-free for five years.

Following the patient's first pregnancy in March 1977, the disease activity increased and prednisone was restarted. An attempt was made to re-introduce sulfasalazine but again extreme nausea and vomiting precluded its use. From 1977 until 1981, the disease fluctuated but the patient was never completely well despite steroid therapy. The patient was rechallenged with sulfasalazine 250 $\mathrm{mg} /$ day in 1979 and enteric coated sulfasalazine in 1981. On both occasions similar severe symptoms developed which necessitated admission to hospital and resolved once the sulfasalazine was discontinued. As well, the patient became intolerant of prednisone, developing headaches and severe depression.

Because of the drug intolerances, the patient was started on azathioprine $100 \mathrm{mg} /$ day in 1983. Complete remission was achieved and the patient was weaned off all prednisone in 1984. The patient remained on azathioprine, symptom-free, until 1987 when liver enzymes were noted to be elevated and surgery was advised. During this time, in 1985 , the patient was started on Asacol but developed the same symptoms of vomiting, severe diarrhea and abdominal cramps within 4 to $6 \mathrm{~h}$ of taking one 400 mg tablet. A second attempt two weeks later caused the same adverse reaction.
In January 1987, because there was relative sparing of the rectum, the patient underwent an abdominal colectomy and ileorectal anastomosis. Initially, the patient did well with approximately two to four bowel movements per day. However, in September 1987 the patient complained of an increased number of bowel movements ranging from five to 16 per day. Sigmoidoscopic examination revealed moderate inflammation of the rectum and she was started on betamethasone enemas (Betnesol: Glaxo) and diphenoxylate (Lomotil; G.D. Searle). The patient developed headaches which were attributed to the betamethasone and abdominal bloating which resolved once the diphenoxylate was stopped. The diarrhea continued and the patient complained of nausea, malaise and weight loss and, therefore, was admitted to hospital.

On admission to hospital, the patient was moderately dehydrated but physical examination was otherwise normal The patient was rehydrated and kept nil by mouth. When food was reintroduced. she was having six to eight bowel movements per day. It was decided to try 5-ASA enemas since the patient was intolerant of all other medication.

The patient received a $4 \mathrm{~g}, 60 \mathrm{~mL}$ 5-ASA enema (Salofalk) at 10:00. At 12:00 she began to feel nauseated. At 14:00 she began to vomit and have continuous explosive, watery diarrhea resulting in a fall in blood pressure from $100 / 60$ to $85 / 60 \mathrm{mmHg}$ and a tachycardia of $100 / \mathrm{min}$. The patient was resuscitated with $1 \mathrm{~L}$ of normal saline over Ih and then Ringer's lactate with potassium chloride $20 \mathrm{mEq} / \mathrm{L}$ at $125 \mathrm{~mL} / \mathrm{h}$. By 19:00 the diarrhea and vomiting had abated. No more enemas were given. Two days later the parient was fully recovered and was discharged home. Because of the persistent symptoms and her intolerance to medication, proctectomy and the pelvic pouch procedure were carried out in November 1987.

\section{DISCUSSION}

Despite its effectiveness in treating acute ulcerative colitis, side effects have been reported in up to $20 \%$ of patients taking sulfasalazine $(4,5)$. These reactions may be dose related or idiosyncratic. The most common, but least severe, adverse reactions include nausea, vomiting, anorexia and headache. Heartburn, epigastric distress and diarrhea are occasionally seen. Although serious adverse reactions may involve almost any organ system, they are rare. They include skin eruptions, hepatic and pulmonary dysfunction and neutropenia, agranulocytosis and thrombocytopenia, as well as other hematological abnormalities. Generalized allergic reactions with fever, skin rash, arthralgias and lymphadenopathy have also been reported (6).

Because most of the side effects of sulfasalazine have been attributed to the sulphapyridine moiety, the new 5-ASA preparations have been of great value in the management of patients with ulcerative colitis who are intolerant of sulfasalazine. Recently, however, there have been reports documenting side effects in a small percentage of patients taking oral 5-ASA. These include chest pain, rashes, fever, dizziness, headache and pericarditis (7-9). In addition, worsening of diarrhea and abdominal pain is an unusual but well documented reaction to both oral and rectal sulfasalazine and these effects have been reported following the oral administration of 5-ASA (10-16).

Two reports described four patients who developed an exacerbation of their ulcerative colitis with both sulfasalazine and oral 5-ASA (Asacol) $(15,16)$. The symptoms included nausea, vomiting. abdominal pain and severe profuse diarrhea which was bloody in one of the four patients. As well, three of four patients developed fever. Each of the four patients was rechallenged one to three times with sulfasalazine and one to two times with 5-ASA. In all patients, the time to the onset of symptoms was shorter each time the patient was rechallenged with sulfasalazine or 5-ASA. In addition, symptoms settled quickly following withdrawal of the sulfasalazine or 5-ASA.

The present patient's course resembles these patients, in that the symptoms were similar; nausea, vomiting, abdominal pain and diarrhea. Symptoms were experienced on oral sulfasalazine and 5-ASA as well as 5-ASA enemas. With rechallenge, the symptoms appeared more quickly so that following adminis- 
tration of the 5-ASA enema, the patient became symptomatic within a few hours. Following withdrawal of the drug, symptoms quickly resolved. The present patient's course is similar to that of a previously reported patient who developed nausea, vomiting and abdominal cramps $2 \mathrm{~h}$ after a sulfasalazine enema $1500 \mathrm{mg}$ in $240 \mathrm{~mL}$ of water); one-half an hour later watery stools developed, which soon became bloody. The nausea and cramps lasted $12 \mathrm{~h}(11)$.

5-ASA enemas have been well tolerated during short term administration for two to eight weeks, as well as long term administration up to 16 months (17.18). There have been isolated reports

ACKNOWLEDGEMENTS: The authors thank John K. Murdoch. Drug Information Services, Toronto General Hospital, for his assistance.

\section{REFERENCES}

1. Khan AKA. Piris ]. Truelove SC. An experiment to determine the active therapeutic moiety of sulfasalazine. Lancet 1977:m:892-5

2. Klotz U, Maier K. Fischer C. Heinkel K Therapeutic efficacy of sulfasalazine and its metabolites in patients with ulcerative colitis and Crohn's disease. N Engl] Med 1980;303:1499-502.

3. Van Hees PAM, Bakker JH, Van Tangeren JHM. Effect of sulfapyridine. 5 -aminosalicylic acid and placebo in patients with idiopathic procritis: A study to determine the active therapeutic moiety of sulfasalazine. Gut 1980:21:632-5.

4. Das KM, Eastwood MA. McManus JP. Sircus W Adverse reactions during salicylazosulfapyridine therapy and the relation with drug metabolism and acetylator phenotype. $\mathrm{N}$ Engl ] Med $1973 ; 289: 491-5$

5. Taffet SL. Das KM. Sulfasalazine adverse effects and desensitization Dig Dis Sci 1983;28:833-42.

6. Peppercorn MA. Sulfasalazine, pharmacology. clinical use toxicity, and related new drug development. Ann of dizziness, headache, nausea, constipation. flatulence, burning or local anorectal irritation and alopecia $(16,17)$. Of 24 patients with a history of allergic reactions to sulfasalazine or intolerance due to nausea and vomiting, four $(17 \%)$ developed side effects when given 5-ASA enemas. Three patients developed rash and fever similar to the reaction experienced with sulfasalazine while the fourth patient developed dizziness. All of these reactions occurred within a few hours after the first enema (21). This is the first report, to the authors knowledge, to document severe diarrhea and abdominal pain following administration of 5-ASA enemas. Although the mechanism for

Intern Med 1984,101:377-86

7. Donald IP. Wilkinson SP. The value of 5 -aminosalicylic acid in inflammatory bowel disease for patients intolerant or allergic to sulfasalazine. Postgrad Med ] 1985:61:1047-8.

8 Dew MI. Harries AD, Evans BK. Rhodes J. Treatment of ulcerative colitis with oral 5 -aminosalicylic acid in patients unable to take sulfasalazine Lancet 1983:iisol

9. Habal FM, Greenberg GR. Treatment of ulcerative colitis with oral 5 -aminosalicylic acid including patients with adverse reactions to sulfasalazine. Am ] Gastroenterol 1988,83:1519.

10. Werlin SL, Grand RJ. Bloody diarrhea: A new complication of sulfasalazine J Pediatr 1978, 92:450-1.

11. Schwartz AG, Targen SR. Saxon A, Weinstein WM. Sulfasalazine induced exacerbation of ulcerative colitis. N Engl ] Med 1982:306:409-12

12. Adler RD, Sulfasalazine-induced exacerbation of ulcerative colitis. $\mathrm{N}$ Engl J Med 1982:307:315

13. Ruppin H. Domschke S. Acute ulcerative colitis, a rare complication of sulfasalazine therapy. Hepatogastroenterology 1984:31:192-3

14. Ring FA, Hershfield NB, Machin GA, Scott RB. Sulfasalazine-induced colitis complicating idiopathic ulcerative colitis. Can Med Assoc] 1984:131:43-5.

15. Austin CA. Cann PA. Jones TH, sulfasalazine induced colitis is unproven. it is presumed to be an allergic phenomenon. The fact that it occurs quickly following ingestion of sulfasalazine or 5-ASA and with decreased time interval following rechallenge is supportive evidence of this mechanism (22).

In conclusion, although 5-ASA is usually well tolerated by most patients, even by those who have experienced side effects from sulfasalazine, it appears that diarrhea and abdominal pain associated with sulfasalazine are due to the 5-ASA moiety. Thus, patients who have experienced these symptoms will likely be intolerant of oral and rectal 5-ASA preparations.

Holdsworth CD, Exacerbation of diarrhea and pain in patients treated with 5-aminosalicylic acid for ulcerative colitis. Lancet 1984:1:917-8.

16. Chakraborty TK, Bhatia D. Heading RC, Ford M] Salicylate induced exacerbation of ulcerative colitis. Gut 1987,28:613-5

17. Bondesen S. Rasmussen SN, Rask-Madsen J, et al. 5-Aminosalicylic acid in the treatment of inflammatory bowel disease. Acta Med Scand 1987,221:227-42.

18. Guarino J. Chatzinoff M, Berk T. Friedman LS, 5-Aminosalicylic acid in refractory distal ulcerative colitis: Long-term results. Am J Gastroenterol 1987:82:732-7.

19. Bondesen S, Neilsen OH. Jacobsen O. et al. 5-A minosalicylic acid enemas in patients with active ulcerative colitis. Scand J Gastroenterol 1984:19:667-82

20, Kutty PK, Raman KRK. Hawken K. Barrowman JA. Hair loss and 5-aminosalicylic acid enemas. Ann Intern Med 1982:97:785-6.

21. Campieri M, Landfranchi GA. Brignola C, et al 5-Aminosalicylic acid as rectal enema in ulcerative colitis patients unable to take sulfasalazine. L ancet 1984:1:403.

22. Cann PA. The incidence and mechanics of diarrhea with 5-ASA. In: 5 ASA: The State of the Art. Toronto:MES Medical Education Services, 1987:41-5. 


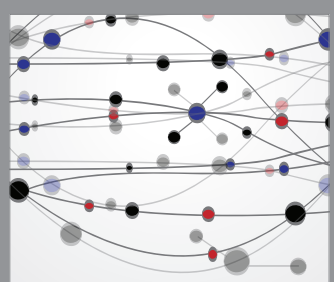

The Scientific World Journal
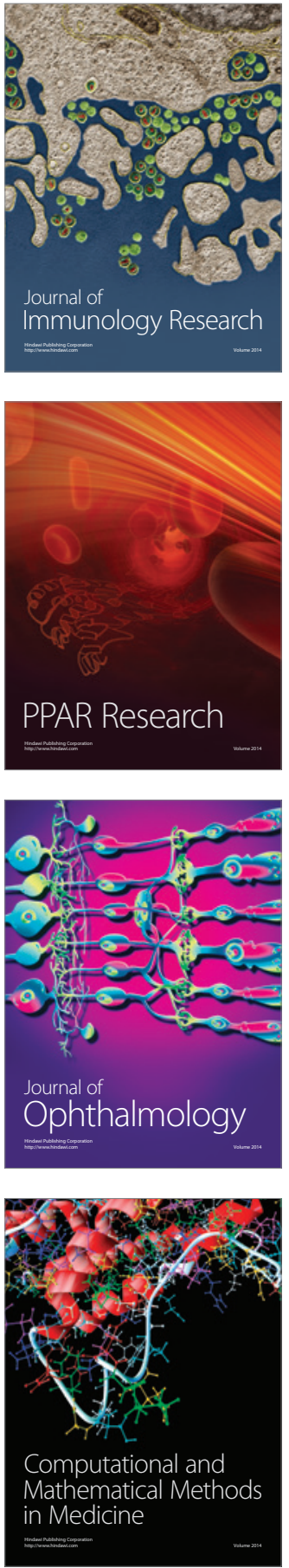

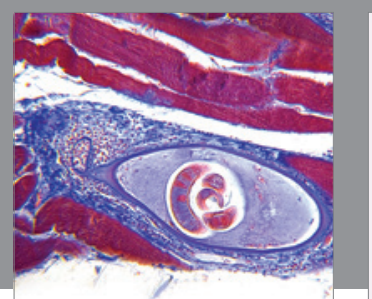

Gastroenterology Research and Practice

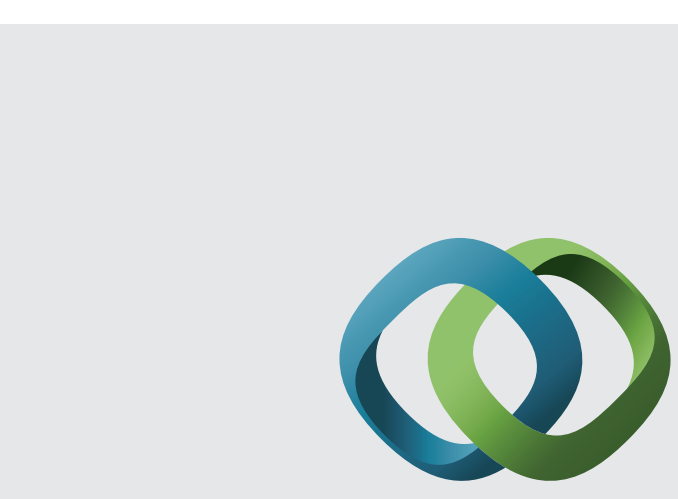

\section{Hindawi}

Submit your manuscripts at

http://www.hindawi.com
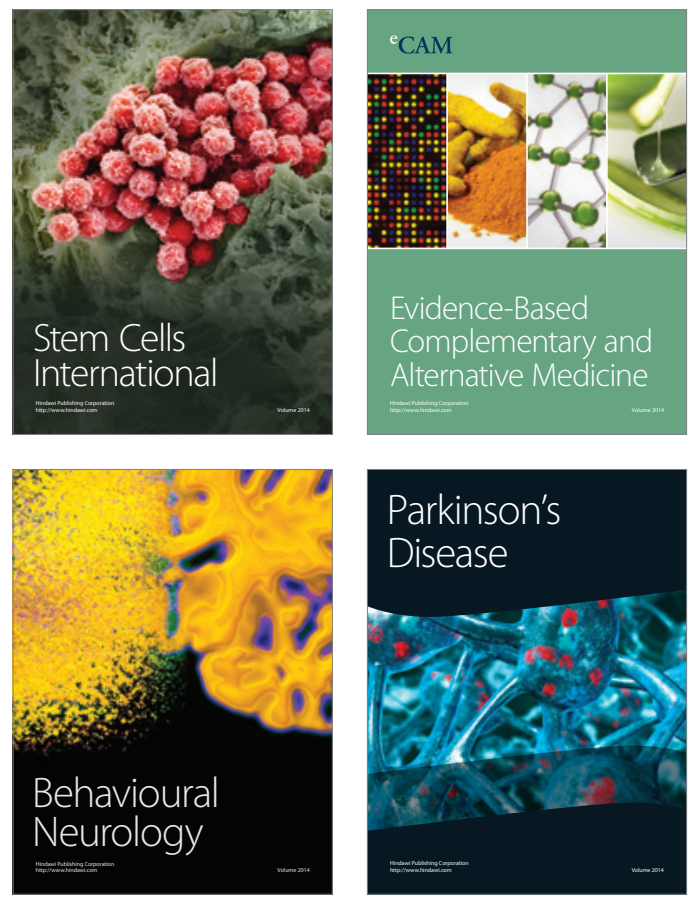
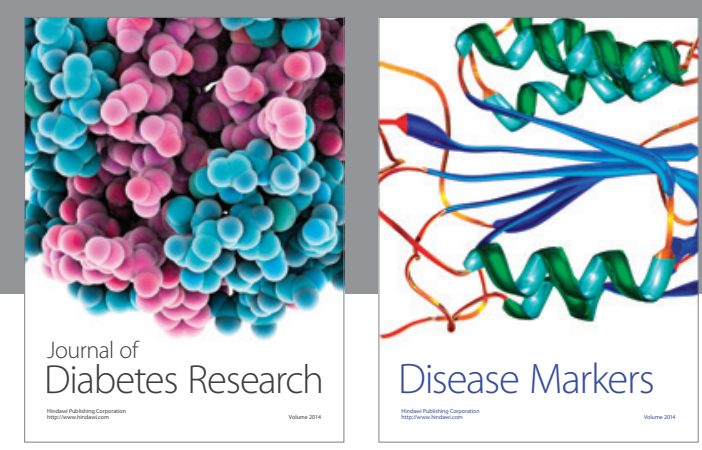

Disease Markers
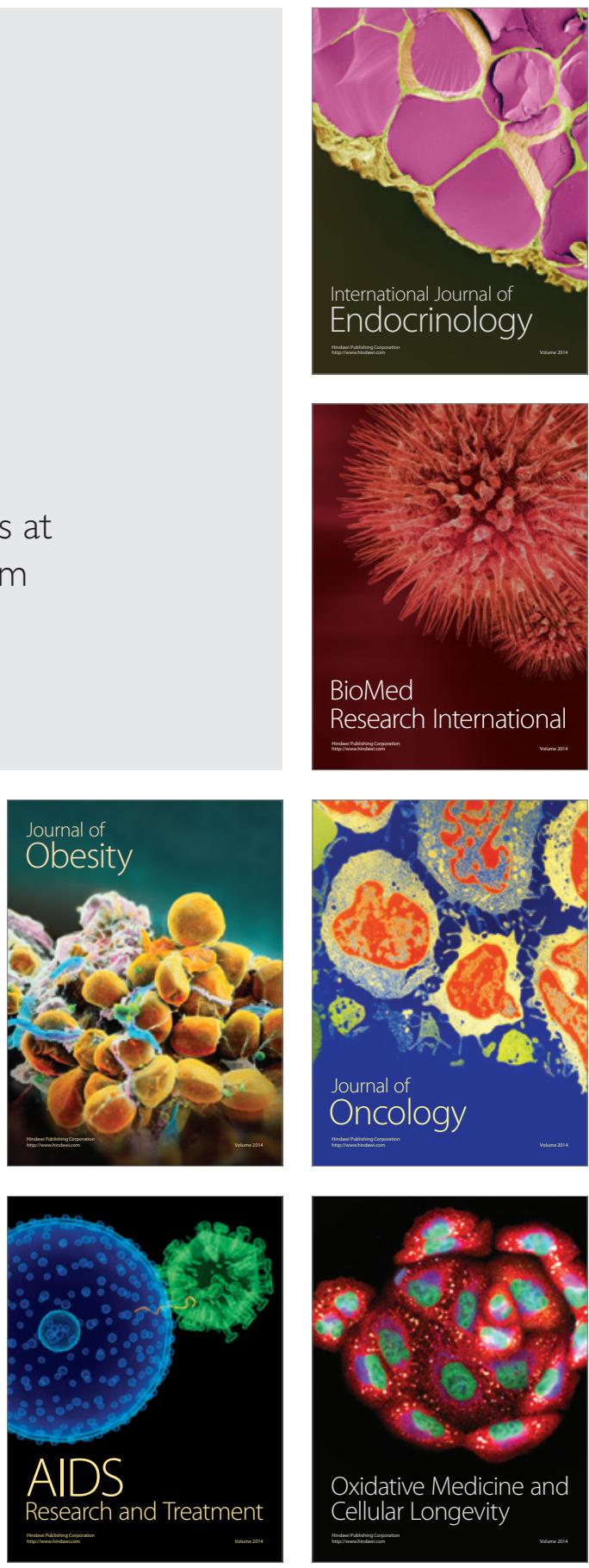